\title{
WORKPLACE VACCINATION MANDATES: MORAL DILEMMAS AND HUMAN RIGHTS
}

\author{
Dragoș BÎGU ${ }^{a^{*}}$, Mihail-Valentin CERNEA ${ }^{b}$ \\ ${ }^{a, b}$ Bucharest University of Economic Studies, Romania
}

\begin{abstract}
This article attempts to provide a normative analysis for decision-making process behind workplace vaccination mandates. To be clear, the paper focuses on employer-based mandates and not situations when public authorities impose some form of compulsory vaccination. The first section of the article presents empirical data about the implementation of workplace vaccination in the case of influenza and COVID-19 and the positive economic effect that vaccination can have on business. The next section argues that employer mandated vaccination puts companies, from an ethical poin of view, in front of a difficult moral dilemma involving the careful balance of both employers' and employees' rights and obligations. The most important part of the framework discusses the relevant factors that need to be taken into account before such measures can be adopted in business and the complications involved by religious and philosophical exemptions. The article ends by concluding that, in the absence of any requirement by public authorities, employers should impose vaccination in quite limited context and, as such, measures to promote vaccination in the workplace without compulsion are more appropriate in a majority of situations.
\end{abstract}

KEYWORDS: bodily integrity, employer vaccination mandates, freedom of religion

DOI: $10.24818 / \mathrm{IMC} / 2021 / 05.02$

\section{INTRODUCTION}

In this paper, we will examine under which conditions vaccine workplace mandates are ethically justified. Although the main point of interest behind this topic is the actual debate on COVID-19 vaccination, the most part of the discussion is relevant for other vaccine mandates as well. Some remarks are needed in order to make the topic of this talk clearer. First, we will strictly confine our discussion to the business perspective. We will not discuss whether mandatory vaccination by law is acceptable. At the same time, we will assume that such workplace mandates are considered legally acceptable, but not obligatory, so businesses are free to decide whether they would enforce mandatory vaccination to their employees. Secondly, although some factual elements on COVID-19 transmission and vaccines will be mentioned, the focus will be on the normative dimension of the issue. The paper will have the following structure: we will begin with a short look at some data available for workplace mandated vaccination as it has been implemented by employers in two cases: influenza and COVID-19. The article will continue by examining the moral dilemma at the heart of workplace mandated vaccination and the human rights at the stake, after which we will provide a general framework which emphasizes the factors that should be considered in any decision by an employer to impose some sort of vaccination (COVID-19 or otherwise) on their employees. The last section will deal with complications posed by religious and religious philosophical that some employees may invoke. We will conclude by drawing normative implications for employers that may consider implementing a vaccination mandate.

\footnotetext{
${ }^{*}$ Corresponding author. E-mail address:dragos.bigu@man.ase.ro
} 


\section{WORKPLACE MANDATED VACCINATION IN THE REAL WORLD}

Before inquiring on the normative aspects of workplace mandated vaccination, it is worth looking at the way vaccination is being mandated by employers and the reason it happens usually in the real world. As we chose to focus the paper on workplace mandates that are not the consequence of regulations imposed by public authorities, we will have to ignore data obtained in situations where there is interference by state regulation.

An interesting study is provided by Graves et al. (2014) in the form of a survey regarding vaccination policies in 583 large employers in the United States in the winter of 2012. While the study explores quite a diverse set of statistics regarding various means to promote vaccination in the workplace, in the interest of this article we find that $14 \%$ of surveyed employers chose to mandate vaccination for access to certain workplace activities. Unsurprisingly, 58\% of these employers were involved in healthcare and social assistance.

Regarding COVID-19, the most recent poll conducted by Mercer on 1000 US employers provided interesting data both on mandates and employee turnover as a result of the mandates. $34 \%$ of employers surveyed had some form of mandate in place: $14 \%$ for all employees, $11 \%$ for onsite employees and $9 \%$ for specific workplace activities. $47 \%$ of healthcare providers, $8 \%$ of tech companies, $29 \%$ of the hospitality industry, $12 \%$ of financial institutions, $2 \%$ of retailers and $4 \%$ of the manufacturing sector require COVID-19 vaccination for all employees. For $71 \%$ of these companies there was no increase in turnover, while $25 \%$ reported a small increase and $4 \%$ experienced rates of turnover larger than 5\% (Mercer, 2021).

Looking at possible economic benefits of vaccination, Samad et al. (2006) examines the vaccination program of a Malaysian petrochemical plan, in which about half of employees chose to vaccinate against seasonal influenza. The lower rate of influenza in the vaccinated group elicited savings for the employer in sick leave costs, totaling 53 US\$ per employee when only labor costs were taken into account and 899.7 US\$ when considering also the operating income of each employee. Another study by Abbas, Fiala and Tawfiq (2006) on influenza vaccination in two major industries in Saudi Arabia, food processing and chemical, also found that influenza vaccination provides net savings per employee vaccinated. This result is further confirmed by another analysis of a Brazilian pharmaceutical company which showed that, as long as the vaccine is effective and at the right price, it can bring substantial benefit to the company (Burckel et al., 1999).

From the data surveyed, we can see that workplace vaccination mandates are a rare occurrence in the labor market, most present in the healthcare industry. On the other hand, during the COVID-19 pandemic an uptick in workplace mandates does occur, but again the healthcare workers are most likely to face a demand to vaccinate from the employer. Lastly, while controversial and, as we are about to explore, an ethical entanglement, vaccines in the workplace do seem to provide net savings to employers.

\section{THE MORAL DILEMMA OF EMPLOYER MANDATED VACCINATION}

The best way to approach an ethical analysis of employer mandated vaccination is to recognize that it is a genuine moral dilemma that entails a difficult balance of rights and obligations by both the employer and the employee. The decision-making process is made even more difficult for the private employer, as it is not a public authority and, thus, has limited means and low political legitimacy to curtail employee rights, particularly when their basic human rights are considered. The employee rights and freedoms at stake generally include the right to bodily integrity and mental health, freedom of conscience and freedom of religion. The right to bodily integrity is affected because vaccination requires the ingestion of a foreign substance and possible side-effects, while mental health can involve certain phobias that can be disabling in significant ways. The political rights of workers must also be considered, as employers may need to apply exemptions for those 
that object to vaccination on philosophical or religious grounds. Employees also have moral obligations that need to be accounted for - the importance of herd immunity and the possible harm it failing to achieve can bring to innocents or the obligation to share the "burden" of vaccination (Uszkai \& Socaciu, 2021). Employers on the other hand must consider their moral and legal obligations to ensure a safe workspace, consumer rights and, when they do apply, fiduciary duties. The employers, however, also have the right to lawfully dismiss employees, though given the kind human rights involved, its applicability in the case of workplace mandated vaccination is limited.

Any employer vaccination mandate is at a normative level an answer to the moral dilemma as it particular to the context of the company involved. Some companies that have limited contact with consumers will have a different moral matrix to companies that work with people that have compromised immune system.

\section{TOWARDS A CONTEXTUAL RIGHTS-BASED SOLUTION}

In this section we will examine in a rights-based approach under which conditions vaccination policies enforced by businesses are ethically acceptable. Employees that do not want to get vaccinated can claim two main rights: the right to bodily integrity and, in some cases, right to freedom of thought and religion. As we will discuss, these rights are not absolute, but can be limited in some cases. On the other side, employers that want to enforce vaccine mandates can claim the right to health. We will discuss the nature and importance of each right involved and afterwards we will examine the conflict between them

The right to bodily integrity is a result of a more general right to autonomy, which states that people have the right to make their own decisions, without interference, since other people are not harmed. The right to bodily integrity is fundamental, since control of own body is an essential part of human autonomy. It is mentioned, for instance, in the Article 3 of the Charter of the Fundamental Rights of European Union, where it is mentioned that in the medical field it includes free and informed consent. The right to bodily integrity includes the right to refuse medical treatment, and therefore the right to refuse vaccination. We would like to add that some people have a general fear to take medication and refuse not only vaccines, but medicines as well. For such people, the right to refuse medication is even more important. It can be said that pharmacophobia can be considered a justification for medical exemption, but this is only a partial solution, since people without diagnosed pharmacophobia can have serious fear of medication.

The second right that can be claimed by employees is the right to freedom of thought and religion. This right is also relevant for the workplace, where employer has a duty to accommodate employee's religious beliefs and the employee has the right to refuse job tasks, if this does not significantly harm employer's business interests. Freedom of religion also includes the right to refuse complying with some workplace policies, if this does not pose undue hardship for employer. Employees can also refuse to comply with mandatory vaccination for religious reasons. However, most churches do not reject vaccination and many explicitly support it, and this raises a further question: In which situation is refusal on religious grounds justified? Since different individuals and even members of clergy can interpret religious commandments in diverse ways, it can be argued that a religious doctrine of a certain confession should be defined by the interpretation of its church leaders. If this is the case, religious exemptions would be very seldom justified.

In addition to the right to freedom of religion, many countries recognize the right to freedom of thought, which refers to a philosophical, instead of a religious, belief. This is a normal extension of a right to freedom of religion, in a society in which there are many non-religious persons, who adhere to pervasive and serious beliefs. Despite this, a philosophical belief is in many cases more difficult to delimit than a religious belief. Vegetarianism is one of the standard examples of a coherent and serious philosophical belief that is sincerely supported by many people and is relevant for workplace situations. In many situations, vegetarianism was considered in courts a philosophical 
belief that deserves protection (McKeown\&Dunn, 2021, pp. 229-232). In relation to vaccination, vegetarianism is a belief that can be relevant, since vegetarian employees can refuse to use vaccines whose production involves the use of animal and human fetal cells (Kraus, 2001, p. 197). However, the problem is complicated by the fact to a certain degree, many people that oppose vaccination can claim a certain personal sincere belief, which would justify their decision. The line between such a belief that would justify refusal of vaccination and a belief that meet the criteria for being protected is not clear-cut, which can lead to many debates in particular cases.

Even if we can accept that the three rights presented above are relevant and important, one can argue that they can be limited for health reasons. During a pandemic, employees are put at risk, and employers have an obligation to decrease the risk. Since mandatory vaccination contributes to a safer workplace, the argument runs, employers have an obligation to enforce it. Furthermore, in most businesses, other parties (business partners, customers) can be put at risk and vaccination contributes to decreasing the risk. In this approach, in the conflict between the right to bodily integrity and the right to health and safety, the latter one should take priority.

We don't think that this approach works. The nature of the rights involved - in this case, the right to bodily integrity and the right to health - is not sufficient to resolve the conflict of rights. Generally, it is very difficult to establish a hierarchy of rights for two reasons. First, in the absence of a specific context, the description of the rights is too general to help us resolve the conflict. Secondly, establishing a general priority of a right over another would lead to a general decision upon any future conflict of rights in which the two rights are involved, but future can bring new and completely unexpected situations, that we don't want to decide in advance. As a result, there is no recognized hierarchy of human rights (Meron, 1986, p. 22) and of rights in general.

If we consider this particular conflict of rights, it is even more clear that a general priority of the right to health and safety cannot be stated: in many industries a completely safe work environment is impossible to provide, and safety is not considered an absolute value, but is often traded off against profitability and other values. In conclusion, we cannot state a general priority of the right of health and safety. Actually, the priority of one of the conflicting rights depends on some factors, which we will analyze further.

The first relevant factor is how important the vaccination of all employees is for the business. If, for instance all employees worked from home, mandatory vaccination would not be justified. The factors that should be taken into account in assessing how vital the vaccination is for a business are vulnerability of employees and customers and the risk of transmission in relation to these categories. Customers' vulnerability - extreme in some cases - could justify mandatory vaccination of healthcare workers. It should be mentioned that this analysis should be taken at the business level: importance of vaccination for the whole society could justify a legal regulation, but not a workplace policy. Workplace vaccination mandates should be proportionate to the risks of transmission.

The second factor is how safe the vaccine is (Savulescu, 2021). It is reasonable to require government authorization for a vaccine in order to accept a workplace mandate. At the same time, for some employees, vaccination might raise a higher risk, and this should give the right to medical exemption. The availability of alternative solution in order to ensure a safe workplace is the third relevant factor (Savulescu, 2021). Even in cases when vaccines are safe, employees can consider vaccination extremely burdensome for employees. For this reason, if businesses can provide alternative solutions for preventing transmission (medical masks, testing, ensuring distance, work from home), they should accept these alternative measures.

In the end of this section, we will briefly examine another possible justification for introducing vaccination mandates. It can be argued that any company has the right to protect its business interest and this is sufficient to justify mandatory vaccination, since spread of the disease among employees could lead to huge losses for the employer (sick days leave, temporary closure of the business etc.). At the same time, for some businesses, for instance restaurants, clients can tend to 
choose the product or services of a certain business or to avoid others as a result of their vaccination policies. Even if this justification is correct, in a right-based perspective it is mostly reducible to the previous justification, based on employees' and customers' right of health and safety.

\section{CONCLUSION}

Workplace vaccination mandates, when not required by public authorities, is a practice that is sparsely used in the business world and for legitimate reasons. As we have already seen, most employers who impose vaccines involve health and social workers who frequently encounter people vulnerable to disease. We have shown that play here is a moral dilemma that private entities are normatively ill equipped to solve, limiting their moral right to mandate vaccination in particular contexts in which stakeholders can be seriously harmed, the vaccine involved is safe and there are no other alternatives available.

This is why a more appropriate solution for most contexts could be to adopt policies to encourage vaccination between employees. They are less debatable as they do not involve the possible breach of human rights and they have already proven successful in driving sick leave days down and increase the customers' confidence. As of this moment $15 \%$ of US employers offer workers that vaccinate for COVID-19 cash and gift cards (Mercer, 2021). For example, Walmart and Target offer one-time payments to employees that choose to get the COVID-19 vaccine. Other possible means to encourage vaccination is to allow it to happen on company time, to provide onsite vaccination and to provide it free of charge.

\section{REFERENCES}

Abbas, M., Fiala, L. \& Tawfiq, L. (2006). Workplace influenza vaccination in two major industries in Saudi Arabia: a cost benefit analysis. J Egypt Public Health Assoc., 81(1-2), 59-73.

Burckel, E., Ashraf, T., de Sousa Filho, J. P. G., Neto, E. F., Guarino, H., Yauti, C., de Barros Barreto, F. \& Champion, L. (1999). Economic impact of providing workplace influenza vaccination. Pharmacoeconomics, 16(5), 563-576.

Graves, M. A., Harris, J. R., Hannon, P. A., Hammerback, K., Ahmed, F. \& Zhou, C. (2014). Workplace-based influenza vaccination promotion practices among large employers in the United States. Journal Of Occupational And Environmental Medicine, 56(4), 397-402.

Kraus, C. L. (2001). Religious Exemptions - Applicability to Vegetarian Beliefs, Hofstra Law Review, 30(1), 197-224

McKeown, P. \& Dunn, A. R. (2021). 'Life-Style Choice' or a Philosophical Belief?: The Argument for Veganism and Vegetarianism to be a Protected Philosophical Belief and the Position in England and Wales, Liverpool Law Review, 42(2), 207-241.

Mercer. (2021). Survey Looks at Vaccine Mandates and Employee Turnover. Retrieved November 3, 2021, from https://www.mercer.us/our-thinking/healthcare/survey-looks-at-vaccinemandates-and-employee-turnover.html

Meron, T. (1986). On a Hierarchy of International Human Rights. The American Journal of International Law, 80(1), 1-23.

Samad, A. H., Usul, M. H., Zakaria, D., Ismail, R., Tasset-Tisseau, A., Baron-Papillon, F. \& Follet, A. (2006). Workplace vaccination against influenza in Malaysia: does the employer benefit? Journal of occupational health, 48(1), 1-10.

Savulescu, J. (2021). Provide Vaccines, Not Require Immunity or Vaccination Passports For Now, The Journal of Law, Medicine \& Ethics, 49(2), 303-306.

Uszkai, R. \& Socaciu, E. (2021). O analiză etică a vaccinării obligatorii. In A. Volacu, D. Cutaș, A. Miroiu (eds.), Alegeri morale. Teme actuale de etică aplicată (pp. 269-296). Iași: Polirom 